\title{
DISTRIBUTION OF RESPIRATORY GASES IN A CLOSED BREATHING CIRCUIT. II. PULMONARY FIBROSIS AND EMPHYSEMA
}

\author{
By A. COURNAND, H. C. A. LASSEN AND D. W. RICHARDS, JR. \\ (From the Department of Medicine, College of Physicians and Surgeons, Columbia University, \\ and the Presbyterian Hospital, New York City)
}

(Received for publication August 11, 1936)

In the preceding paper (1) we have shown that in a small closed breathing circuit of steadily diminishing volume (due to absorption of oxygen and $\mathrm{CO}_{2}$ ), any inert gas in the system will not be evenly distributed, when mixture of all respiratory gases reaches equilibrium. Due to the fact that the lungs are a reservoir containing air from many earlier breaths with correspondingly lower concentrations of nitrogen (or other foreign inert gas), the pulmonary air at any moment contains a lower nitrogen concentration than the spirometer.

It was found that with quiet breathing by normal subjects, tidal air was sufficiently well distributed through pulmonary spaces, so that by sampling either expired air or deep alveolar air, the concentration of nitrogen in the pulmonary air could be measured fairly accurately. By the use of this value as well as that of the sample from the spirometer, at the end of a period of from 6 to 8 minutes' quiet breathing, functional residual air could be calculated.

In the present investigation we have attempted to extend the same method of study to a group of cases of pulmonary fibrosis and emphysema.

It is clear that in the system under consideration, the lag in nitrogen concentration within the lungs, or difference between the nitrogen concentrations of inspired air and expired air, will depend upon a number of variables, among which are the volume of residual air in the lungs, the volume of effective tidal air (actual tidal air minus pulmonary dead space), the rate of change of inspired nitrogen (and oxygen) concentrations per breath.

Tidal air varied between $300 \mathrm{cc}$. and $600 \mathrm{cc}$, in the cases that we studied. Change in inspired nitrogen concentration per breath varied between 0.25 and 0.40 per cent.

If the functional residual air is small, one would expect that there would be a more effective washing out of pulmonary air spaces with each breath, and less " oxygen storage" or " nitrogen lag" in the lungs during the closed circuit breathing.

We have made measurements of functional residual air in a group of cases of pulmonary fibrosis and other conditions tending to reduce residual air volume. The method used was that of Christie (2), modified by the additional use of alveolar air samples taken both before and at the end of the period of breathing in the closed circuit, as described in the preceding paper (1).

\section{TABLE I}

Functional residual air, calculated $(I)$ by assumption of equal mixture of nitrogen through system; (II) by actual measurement of expired (alveolar air) nitrogen

\begin{tabular}{l|c|c|l|c|c}
\hline \hline Subject & Age & Sex & & \multicolumn{2}{|c}{ Condition } \\
& & & & \multicolumn{2}{|c}{$\begin{array}{c}\text { Functional } \\
\text { residual air }\end{array}$} \\
& & & & I & II \\
\hline & years & & & $c c$. & $c c$. \\
H. L. & 38 & M & Normal & 3660 & 3410 \\
D. R. & 40 & M & Normal & 4690 & 3518 \\
A. C. & 40 & M & Normal & 2380 & 2210 \\
S. F. & 25 & M & Tuberculosis, fibrosis & 2990 & 2570 \\
G. L. & 38 & M & Tuberculosis, fibrosis & 2405 & 2300 \\
F. W. & 28 & F & Tuberculosis, fibrosis & 1530 & 1400 \\
A. M. & 27 & F & Tuberculosis, thoracoplasty & 1168 & 1153 \\
D. M. M. & 50 & M & Old empyema, fibrosis & 1138 & 1128 \\
\hline
\end{tabular}

Table I gives the residual air values for five such cases, and for three normal individuals. The principal pulmonary abnormalities of each case are listed. Each of these cases of pulmonary fibrosis was also studied quite extensively from the point of view of circulatory and pulmonary function. These details need not be reviewed here, but it is important to note that none of the cases had evidence of much disturbance in pulmonary gas exchange, or in distribution of tidal air through the lungs: that is, $\mathrm{CO}_{2}$ levels of alveolar air and of arterial blood were within normal limits, resting ventilation was not in- 
creased (cf. Nielsen and Sonne (3)), and arterial oxygen saturation was normal at rest. (For technique of these studies see Cournand et al. (4)).

In Table I, the functional residual air has been calculated in two ways : first, assuming equal mixture of inert gas (nitrogen) through the system, and second by the use of actual pulmonary (alveolar) samples. It will be seen that the difference between the results by the two methods of calculation is less, the smaller the functional residual air. This is due largely to the fact (as predicted above) that with small functional residual air, concentration of nitrogen in expired air is not less than that in inspired, but is either the same or larger. In other words, the " nitrogen lag" in the lungs is much less than is the case with normal individuals having larger residual lung volumes. A given volume of tidal air washes out the existing residual air more effectively.

We may consider now the application of this method of study to cases of pulmonary emphysema.

Theoretically, as indicated above, a large residual air will tend to increase the "nitrogen lag" in the lungs, after the distribution of gases in the closed breathing circuit has reached equilibrium. It is possible to calculate what will be the expected nitrogen percentages in lungs and spirometer (or in inspired and expired air samples), after a given number of breaths, in a system with known values of residual air, tidal air, pulmonary dead space, and change per breath in nitrogen concentration of inspired air. As values typical of advanced emphysema we have chosen the following :

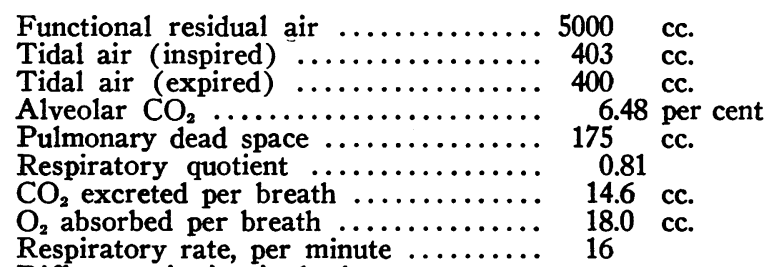

Difference in inspired nitrogen concen-

tration, per breath ................ 0.25 per cent

The calculation is carried out in a manner similar to that described in the preceding paper. As one would expect, with larger residual air and smaller effective tidal air, it takes longer for an equilibrium state to be established, than was the case with the normal values. It required, as a matter of fact, about 40 breaths before this equilibrium state existed, in the calculation with the above values. Table II shows the essential re-

TABLE II

Calculated changes in concentrations of respired gases, in closed circuit, with progressively decreasing inspired oxygen concentrations

\begin{tabular}{|c|c|c|c|c|c|c|}
\hline \multirow{2}{*}{$\begin{array}{l}\text { Assumed } \\
\text { residual air }\end{array}$} & \multirow{2}{*}{$\begin{array}{c}\text { Number of } \\
\text { breaths }\end{array}$} & \multicolumn{2}{|c|}{ Oxygen } & \multicolumn{2}{|c|}{ Nitrogen } & \multirow[b]{2}{*}{ R.Q. } \\
\hline & & $\begin{array}{c}\text { In- } \\
\text { spired }\end{array}$ & $\underset{\text { pired }}{\text { Ex- }}$ & $\begin{array}{c}\text { In- } \\
\text { spired }\end{array}$ & $\underset{\text { pired }}{\text { Ex- }}$ & \\
\hline Normal & & $\begin{array}{l}\text { per } \\
\text { cent }\end{array}$ & $\begin{array}{l}\text { per } \\
\text { cent }\end{array}$ & $\begin{array}{l}\text { per } \\
\text { cent }\end{array}$ & $\begin{array}{l}\text { per } \\
\text { cent }\end{array}$ & \\
\hline 2160 cc. & $\begin{array}{l}\text { 1st breath } \\
\text { 10th breath } \\
12 \text { th breath }\end{array}$ & $\begin{array}{l}49.75 \\
47.50 \\
47.00\end{array}$ & $\begin{array}{l}44.40 \\
42.60 \\
42.15\end{array}$ & $\begin{array}{l}50.25 \\
52.50 \\
53.00\end{array}$ & $\begin{array}{l}50.10 \\
52.10 \\
52.35\end{array}$ & $\begin{array}{l}0.92 \\
1.00 \\
1.01\end{array}$ \\
\hline $\begin{array}{c}\text { Emphysema } \\
5000 \text { cc. }\end{array}$ & $\begin{array}{l}\text { 1st breath } \\
15 \text { th breath } \\
20 \text { th breath } \\
\text { 30th breath } \\
\text { 40th breath }\end{array}$ & $\begin{array}{l}49.75 \\
46.25 \\
45.00 \\
42.50 \\
40.00\end{array}$ & $\begin{array}{l}43.48 \\
42.11 \\
41.35 \\
39.57 \\
37.52\end{array}$ & $\begin{array}{l}\mathbf{5 0 . 2 5} \\
\mathbf{5 3 . 7 5} \\
\mathbf{5 5 . 0 0} \\
\mathbf{5 7 . 5 0} \\
\mathbf{6 0 . 0 0}\end{array}$ & $\begin{array}{l}50.04 \\
51.41 \\
52.17 \\
53.95 \\
56.00\end{array}$ & $\begin{array}{l}0.92 \\
1.34 \\
1.49 \\
1.80 \\
2.09\end{array}$ \\
\hline
\end{tabular}

sults of this calculation, and compares them with those already given for normal values in Table II of the preceding paper (1). It will be noted how marked a discrepancy exists after 30 or 40 breaths, between inspired and expired air ; resulting in an excess of 4 per cent in nitrogen concentration of inspired over expired air, and a respiratory quotient over 2.0.

It should be noted, in this calculation just as in that of the preceding paper, that we have made several assumptions here, especially that each inspired breath (exclusive of the pulmonary dead space) is evenly distributed throughout the functional residual air. Also, nitrogen excretion from the lungs has not been accounted for in our calculation; this would tend to increase expired nitrogen values slightly.

If, however, the conditions represented by the calculation are approximately fulfilled in emphysematous subjects, one would expect that the nitrogen concentration of expired air would be much less than inspired air, and that residual air calculated by the assumption of equal mixture of nitrogen through the system would have a much greater value than residual air calculated by the use of actual pulmonary nitrogen concentrations.

To test this postulate, we have made experiments, similar to those described in the preceding 
paper, on several subjects with marked pulmonary emphysema. In these experiments, corresponding samples of inspired and of expired air were obtained, at the end of 6,7 , and 8 minutes' breathing in the closed circuit; and alveolar samples obtained before the closed circuit breathing began, and at the end of the eighth minute. The results of an experiment on each of two emphysematous subjects are given in Table III.

\section{TABLE III}

Emphysema. Composition of inspired $(A)$ and expired (B) air, with progressively decreasing oxygen concentration in inspired air

\begin{tabular}{|c|c|c|c|c|c|c|c|c|}
\hline \multirow{2}{*}{ Specimen } & \multicolumn{2}{|c|}{$\mathrm{CO}_{2}$} & \multicolumn{2}{|c|}{$\mathrm{O}_{2}$} & \multirow{2}{*}{ RQ } & \multicolumn{2}{|c|}{$\mathrm{N}_{2}$} & \multirow{2}{*}{$\Delta \mathrm{N}_{2}$} \\
\hline & $\boldsymbol{A}$ & $B$ & $A$ & $B$ & & $\boldsymbol{A}$ & $B$ & \\
\hline & $\begin{array}{l}\text { per } \\
\text { cent }\end{array}$ & $\begin{array}{l}\text { per } \\
\text { cent }\end{array}$ & $\begin{array}{l}\text { per } \\
\text { cent }\end{array}$ & $\begin{array}{l}\text { per } \\
\text { cent }\end{array}$ & & $\begin{array}{l}\text { per } \\
\text { cent }\end{array}$ & $\begin{array}{l}\text { per } \\
\text { cent }\end{array}$ & $\begin{array}{l}\text { per } \\
\text { cent }\end{array}$ \\
\hline
\end{tabular}

SUBJECT S. B., FEBRUARY 18, 1936

\begin{tabular}{c|c|c|c|c|c|c|c|c}
\hline $\begin{array}{c}\text { Alveolar, be- } \\
\text { fore........ }\end{array}$ & .03 & 6.2 & 20.9 & 12.3 & 0.72 & 79.1 & 81.5 & -2.4 \\
7th minute. . & .02 & 5.1 & 26.6 & 22.1 & 1.08 & 73.4 & 72.8 & +0.6 \\
8th minute... & .06 & 5.3 & 22.9 & 18.3 & 1.15 & 77.0 & 76.4 & +0.6 \\
$\begin{array}{c}\text { Alveolar, 8th } \\
\text { minute..... }\end{array}$ & .06 & 7.2 & 22.9 & 15.9 & 1.03 & 77.0 & 77.0 & 0 \\
\hline
\end{tabular}

SUBJECT F. S., FEBRUARY 19, 1935

\begin{tabular}{c|c|c|r|r|r|r|r|r}
\hline $\begin{array}{c}\text { Alveolar, be- } \\
\text { fore......... }\end{array}$ & 0 & 8.4 & 20.9 & 9.5 & .74 & 79.1 & 82.1 & -3.0 \\
7th minute... & 0 & 5.4 & 38.9 & 33.7 & 1.04 & 61.1 & 60.9 & +0.2 \\
8th minute... & 0 & 6.0 & 36.1 & 31.1 & 1.20 & 63.8 & 62.9 & +0.9 \\
$\begin{array}{c}\text { Alveolar, 8th } \\
\text { minute...... }\end{array}$ & 0 & 8.8 & 36.1 & 26.2 & .89 & 63.8 & 65.0 & -1.2 \\
\hline
\end{tabular}

Both these subjects had advanced generalized pulmonary emphysema, with chronic bronchitis but without clinical evidence of any large localized pulmonary infection; nor any evidence of cardiac failure. The first patient, S. B., was a man of 38 , whose symptoms were cough, and severe dyspnea, occurring always on slight exertion, and frequently in paroxysms even at rest. Physical examination showed characteristic signs of emphysema. His vital capacity was about 1,200 cc., his residual lung volume (according to our measurements) greatly increased. Arterial blood was 90 per cent saturated at rest. His symptoms were somewhat relieved by continuous oxygen therapy.

The second patient, F. S., was a man of 54 who had had chronic sinusitis for many years, and for several years past, increasing cough and dyspnea on exertion. He was moderately cyanotic. Habitus was asthenic, with long chest, and atonic abdomen. Chest signs were characteristic of emphysema. The heart was not enlarged. Measurements of lung volume were variable, vital capacity varying from $1,500 \mathrm{cc}$. to $3,100 \mathrm{cc}$. (after adrenalin). Measurements of residual air were always high, though also variable. Intrapleural pressure was +10 , -5 . Arterial blood was markedly unsaturated, even at rest, varying between 78 and 88 per cent oxygen saturation. The patient was somewhat relieved by oxygen therapy, greatly relieved by adrenalin.

Examination of the figures in Table III shows, in the first place, in both subjects, a considerable discrepancy between the $\mathrm{CO}_{2}$ and oxygen values of expired air as compared with corresponding values of alveolar air, at the end of the 8th minute. This discrepancy is greater than can be accounted for on the basis of the time taken by these patients ( 8 seconds by S. B., 10 seconds by F. S.) in making an extreme expiration, after a normal expiration. In the case of F. S., with the more marked emphysema, oxygen absorption in 10 seconds was about $50 \mathrm{cc}$., $\mathrm{CO}_{2}$ output about $40 \mathrm{cc}$. Functional residual air, as measured, was $5,845 \mathrm{cc}$. Thus, the $\mathrm{CO}_{2}$ content of the residual air, according to the expired air value, would be $(5,845 \times$ $.060)=351 \mathrm{cc}$. ; whereas according to the alveolar air value it would be $(5,845 \times .088)-40=$ 465 cc. Correspondingly, the oxygen content of the residual air, according to the expired air value, would be $(5,845 \times .311)=1,818 \mathrm{cc}$. ; according to the alveolar air value, would be $(5,845 \times .262)$ $+50=1,582$ cc.; a difference of 236 cc. The difference in nitrogen concentration of expired as compared with alveolar samples (Table III) is a further index of inequality of deep alveolar as compared with the last part of the expired tidal air.

Thus we have in the emphysematous subject evidence of considerable inequality of concentrations of respiratory gases through the lungs. This concept is not new. The most conclusive recent investigations have been those of Sonne and his collaborators $(3,5)$, who have shown that even in normal individuals there are alveolar spaces which are hypoventilated; whereas in emphysematous subjects this tendency becomes 
very much more pronounced. In normal subjects there are apparently certain alveolar spaces which, though hypoventilated are also hypoperfused, so that the air in them is not greatly vitiated, $\mathrm{CO}_{2}$ being less in this air, and oxygen greater, than in other alveolar spaces. In patients with emphysema, on the other hand, all deeper alveolar air is high in $\mathrm{CO}_{2}$ and very low in oxygen, suggesting that the poorly ventilated regions are still relatively over-perfused by pulmonary blood.

It has been recognized for some years that the Haldane-Priestley "alveolar" specimen is a more or less empirical function; as evidenced by the fact that the correspondence in $\mathrm{CO}_{2}$ tension between alveolar sample and arterial blood depends upon the particular technique of obtaining this sample; and that this technique is different for different physiological conditions, such as rest and exercise. With Sonne's concept of the distribution of gases within the lungs, the HaldanePriestley sample becomes frankly a roughly approximate mixture of air from various regions of the lungs.

In the case of the patient F. S., several determinations of the deepest possible alveolar air were found to be approximately the same in $\mathrm{CO}_{2}$ tensions, as the $\mathrm{CO}_{2}$ tension of arterial blood drawn at the same time. This suggests that there are regions in the lungs in which the air is more vitiated than that in the alveolar specimen; as well as hyperventilated regions in which the air is less vitiated.

Returning to the inspired and expired air values in Table III, we find that they are consistent with the concept just discussed. That is, the concentration of nitrogen in the expired air is not 3 or 4 per cent less than that in the inspired air, as one would expect from our calculations, but is less than one per cent less. This suggests that the volume into which the tidal air passes and in which it mixes with the air of earlier inspired breaths is about the same as the residual air volume of normal individuals (see data in preceding paper); rather than the much larger volume of total residual air in this emphysematous subject. The above suggestion is of course not to be construed strictly anatomically. Instead of a certain volume into which all tidal air is well and evenly distributed, there probably exists a certain reduced volume in which this even distribution takes place, and in addition a large volume which some tidal air reaches but only in very small amount at each breath, so that such spaces contain at all times greatly vitiated air. The greater nitrogen concentration that always exists in deep alveolar specimens, as compared with that in the corresponding specimens of expired air, is consistent with this notion.

In a clinical case of emphysema there is apt to be much variation, from day to day, or even from hour to hour, in the severity of symptoms; and one would naturally expect corresponding variability in distribution of air through pulmonary spaces; associated with changes in patency of air passages, and in other functions. In a number of experiments, of the type illustrated in Table III, on a group of five emphysematous patients, our results quantitatively with each patient were quite variable. Expired air nitrogen was sometimes considerably less than inspired air, at another time nearly equal, or even greater. The values of alveolar air gases, and the relations between these and the expired air gases, or between these and outside air, were also variable.

Similarly, our efforts to obtain consistent results in values for functional residual air in such subjects, even after applying the correction for actual nitrogen concentrations of alveolar air (see previous paper), were unsuccessful. Some of these variations may have been due to actual change, from day to day, in resting mid-position of the chest; but frequently the variation in figure for functional residual air was considerably greater than could be explained by this factor, or by any probable alteration in pulmonary vascular bed or other anatomical cause.

Table IV gives some values obtained on three emphysematous subjects. Calculations were made as described in the preceding paper. It will be seen that several types of inconsistency exist in these residual air figures. In all subjects there is usually a large correction factor due to the use of actual alveolar air nitrogen values. This is due in part to "oxygen storage " and " nitrogen lag," in part to the fact that with a large amount of nitrogen in the system, dilution with a given volume of oxygen (run into the spirometer before rebreathing begins) causes less percentile change in total nitrogen concentration. The latter factor makes the divisor in the equation small, i.e., nitro- 
TABLE IV

Figures for functional residual air in emphysematous subjects

\begin{tabular}{|c|c|c|c|c|c|c|}
\hline \multirow{2}{*}{ Subject } & \multirow[b]{2}{*}{ Age } & \multirow[b]{2}{*}{ Sex } & \multirow{2}{*}{ Date } & \multirow{2}{*}{\begin{tabular}{|c} 
Num- \\
ber of \\
minutes \\
breath- \\
ing
\end{tabular}} & \multicolumn{2}{|c|}{$\begin{array}{l}\text { Functional } \\
\text { residual air }\end{array}$} \\
\hline & & & & & $\begin{array}{l}\text { I } \\
\text { (assum- } \\
\text { ing equal } \\
\text { mixture) }\end{array}$ & $\begin{array}{l}\text { II } \\
\text { (using } \\
\text { alveolar } \\
\text { samples) }\end{array}$ \\
\hline A. G.. & $\begin{array}{c}\text { years } \\
39\end{array}$ & $\mathbf{M}$ & \begin{tabular}{l}
\multicolumn{2}{c}{$19 \$ 6$} \\
March \\
March
\end{tabular} & $\begin{array}{l}7 \\
6 \\
7 \\
8\end{array}$ & $\begin{array}{c}c c . \\
3280 \\
4160 \\
4215 \\
4410\end{array}$ & $\begin{array}{c}c c . \\
3200 \\
3645 \\
3640 \\
3710\end{array}$ \\
\hline E.P... & 56 & $\mathbf{M}$ & $\begin{array}{l}\text { January } 1 \\
\text { January } 1\end{array}$ & $\begin{array}{l}7 \\
6 \\
7\end{array}$ & $\begin{array}{l}6940 \\
3560 \\
3890\end{array}$ & $\begin{array}{l}5930 \\
2940 \\
2965\end{array}$ \\
\hline S. B.... & 42 & $\mathbf{M}$ & $\begin{array}{l}\text { February } 1 \\
\text { March } \\
\text { March }\end{array}$ & $\begin{array}{l}7 \\
6 \\
7 \\
8 \\
6\end{array}$ & $\begin{array}{l}9150 \\
5420 \\
6550 \\
8960 \\
9390\end{array}$ & $\begin{array}{l}5520 \\
4650 \\
5150 \\
6750 \\
6730\end{array}$ \\
\hline
\end{tabular}

gen concentration in the lungs at the start minus nitrogen concentration at the end. A 2 per cent error in nitrogen concentration (due to failure to use actual alveolar nitrogen concentration) therefore produces a greater proportional effect upon this divisor, than if the divisor were numerically larger.

In Subject A. G. it will be seen that the corrected values for functional residual air, are fairly consistent. In Subject E. P., on the other hand, there occurred in two successive examinations a large and unaccountable difference in residual air value. This subject was particularly cooperative, and technically both tests appeared satisfactory. In Subject S. B. there was not only a very large difference between corrected and uncorrected values, but the former varied widely among themselves.

With Patient F. S., also, we tried for several weeks during the spring of 1934, and again at frequent intervals in the winter and spring of 1935 , to establish a consistent level for functional residual air. Table $\mathrm{V}$ shows the results of a group of experiments. These were technically satisfactory, yet gave most diverse figures.

It will be noted that several of the experiments recorded in Table $\mathrm{V}$ were performed while the patient was in an oxygen chamber, in which the oxygen was maintained at 35 to 50 per cent. The effect of high oxygen upon anoxemic subjects is
TABLE V

Measurements of functional residual air, under various conditions, in emphysematous subject $(\mathcal{F}$. $S$.): $I$, assuming equal mixture in system; II, using actual alveolar nitrogen values

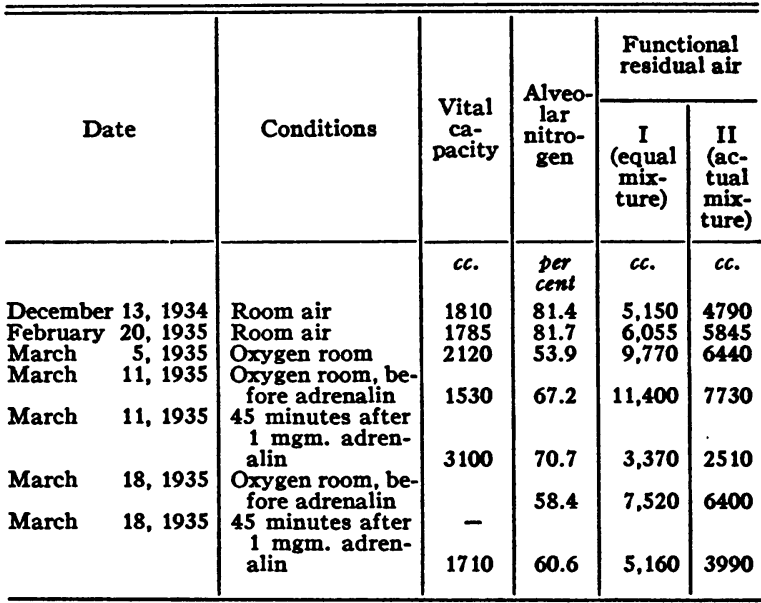

to increase greatly the alveolar and blood $\mathrm{CO}_{2}$ levels, as well as to provide increased arterial oxygen saturation (Richards and Barach (6)). This probably occurs secondary to diminished ventilation of alveolar spaces. Thus, in Patient F. S., the alveolar $\mathrm{CO}_{2}$ increased from about 8 per cent to about 11 per cent. So far as calculations of residual air are concerned this effect should increase the alveolar nitrogen concentration as compared with that of the inspired air; and this in turn will increase the correction factor provided by our formula (see preceding paper) for residual air, a formula which includes alveolar values in the calculation. Table $\mathrm{V}$ demonstrates this. Another factor acting in this same direction is the fact that the divisor in the corrected formula (i.e., the difference between nitrogen of alveolar air before and after the closed circuit breathing) is usually smaller when room air nitrogen is only 60 per cent instead of 79.1 per cent.

Even more striking are the effects of adrenalin, in this patient, upon the residual air figures, as shown in Table V; much greater than the corresponding changes in vital capacity. The mechanism of this is not entirely clear. Presumably, some of the effect is due to more adequate ventilation of deep hypoventilated alveolar spaces; partly because of greater patency of air passages, partly because of the general hyperventilation induced by adrenalin. 
It should be emphasized that the wide discrepancies in these various figures for functional residual air occurred in cases of extreme emphysema. A group of less advanced cases might well have shown more consistent results with the method used.

In conclusion, it seems clear that the unequal distribution of respiratory gases, which has been shown to exist in the lungs of emphysematous subjects, makes it difficult, if not impossible, to obtain reliable measurements of residual air with the method which we have used, of quiet breathing in a small closed circuit. Most of the errors appear to be in the direction of producing figures for residual air that are too large.

We have been experimenting recently with a modified method, which includes a preliminary period of breathing pure oxygen, for the purpose of washing out the nitrogen of hypoventilated alveolar spaces; followed by a period of closedcircuit breathing in which the volume of the system is kept constant, and in which the diluent inert gas is largely helium (with greater diffusing velocity). These experiments are not yet sufficiently advanced to be reported.

\section{SUMMARY}

1. Subjects with small residual lung volumes have correspondingly small " nitrogen lag" within the lungs, after breathing through a small closed circuit whose total volume progressively diminishes. By " nitrogen lag" is meant the excess of concentration of nitrogen in inspired over that in expired air.
2. Subjects with large residual lung volumes (emphysema) would be expected to have large " nitrogen lag." Due, however, to poor distribution of tidal air through the lungs, this does not occur.

3. In emphysematous subjects, poor distribution of tidal air, with hypoventilation throughout a large part of the pulmonary air spaces, may produce large errors in the determination of residual lung volumes by methods of quiet breathing in a closed circuit.

\section{BIBLIOGRAPHY}

1. Lassen, H. C. A., Cournand, A., and Richards, D. W., Jr., Distribution of respiratory gases in a closed breathing circuit. I. In normal subjects. J. Clin. Invest., 1937, 16, 1.

2 Christie, R. V., The lung volume and its subdivision. I. Methods of measurement. J. Clin. Invest., 1932, 11, 1099.

3. Nielsen, E., and Sonne, C., Die Zusammensetzung der Alveolarluft. Ztschr. f. d. ges. exper. Med., 1932, $85,46$.

Sonne, C., Der respiratorische Luftaustausch in den Lungen. Ztschr. f. d. ges. exper. Med., 1934, 94, 13.

4. Cournand, A., Brock, H. J., Rappaport, I., and Richards, D. W., Jr. Disturbance of action of respiratory muscles as a contributing cause of dyspnea. Arch. Int. Med. 1936, 57, 1008.

5. Roelsen, E., Uber die Verteilung der Inspirationsluft in der Alveolarluft. Acta med. Skandinav., 1934, Supp. 59, 356.

6. Richards, D. W., Jr., and Barach, A. L., Prolonged residence in high oxygen atmospheres. Effects on normal individuals and on patients with chronic cardiac and pulmonary insufficiency. Quart. J. Med., 1934, 3, 437. 